\title{
ON THE ALBEDO OF SNOW IN ANTARCTICA: A CONTRIBUTION TO I.A.G.O.*
}

\author{
By GeRD WENDLER and JOHN KeLleY ${ }^{\dagger}$ \\ (Geophysical Institute, University of Alaska, Fairbanks, Alaska 99775-0800, U.S.A.)
}

ABSTRACT. As part of a larger experiment, detailed albedo measurements were carried out during the austral summer of $1985-86$ in the dry-snow zone $(1560 \mathrm{~m})$ of Terre Adélie, eastern Antarctica. The following results were found:

(1) Mean albedo values were high (around $82.6 \%$ ). On clear days, the albedo showed some dependency on the solar elevation. The dependency was slight for solar elevations above $12^{\circ}$ but became larger with low Sun angles.

(2) The albedo was found to be a function of cloud amount and type, increasing with the amount and thickness of clouds. In white-out conditions, very high albedos were found $(>90 \%)$.

(3) The albedo showed a dependency on the type of snow. New snow displayed higher values than older snow, whose crystals had been destroyed by mechanical action.

(4) A simple model was developed to assess the influence of sastrugi on the albedo. This model could explain the asymmetric diurnal variation about solar noon of the measured albedo above a sastrugi field.

The above four dependencies might explain the considerable discrepancies which can be found in the literature concerning the snow albedo of Antarctica.

\section{INTRODUCTION}

The radiation balance of any surface, and with it the surface climate, is influenced by its albedo. If the reflectivity is high, as it is in Antarctica, which is $99 \%$ snow-covered, this dependency is strong, as most of the energy received from the Sun is reflected back into space. Hence, in Antarctica the radiation balance is negative for most of the year. To compensate for this loss, the air warms the surface, thereby losing energy itself. Hence, a cold layer of air normally lies over the Antarctic ice sheet. This inversion layer, being heavier than the air aloft at the same height further down the slope, flows downward (katabatic wind) towards the coast of the Antarctic continent (Mawson, 1915). Therefore, the albedo plays an important role in the heat balance of the whole continent, especially as the snow of Antarctica is mostly dry, and reflects solar radiation very well. There have been a number of excellent studies of this phenomenon (Liljequist, 1956; Hoinkes, 1960; Kuhn and others, 1977, Carroll and Fitch, 1981; Ishikawa and others, 1982; Yamanouchi, 1983). However, great discrepancies in the albedo have been reported, with values around $80 \%$ being normal. This paper, based on measurements in Terre Adélie, eastern Antarctica, tries to resolve some of these discrepancies by considering different physical processes.

*Interaction Atmosphere-Glacier-Ocean.

${ }^{\dagger}$ Institute of Marine Science, University of Alaska, Fairbanks, Alaska 99775-0800, U.S.A.
LOCATION, INSTRUMENTATION, AND TIME OF OBSERVATIONS

About 5 years ago, a joint U.S.-French experiment commenced to investigate the katabatic wind regime in eastern Antarctica (Wendler and Poggi, 1980; Poggi and others, 1982). Associated with this katabatic wind investigation were complementary studies of the surface-heat budget and the albedo. During the austral summer of 1985-86, detailed radiative measurements were carried out at D-47 (lat. $67^{\circ} 23^{\prime} \mathrm{S}$., long. $138^{\circ} 43^{\prime}$ E.) in Terre Adélie (Fig. 1) at an altitude of $1560 \mathrm{~m}$. D-47 is located about $110 \mathrm{~km}$ south of the year-round French Antarctic support station Dumont d'Urville. The gradient of the slope is of the order of $6 \times 10^{-3}$. Furthermore, D-47 is the site of an automatic weather station (AWS), which reports over satellite throughout the year (Renard and Salinas, 1977; Stearns and Savage, 1981). Hence, a large amount of climatological data is available for this site (Wendler and Kodama, 1985). Station D-47 is located above the dry-snow line. This strongly influences the reflectivity of the snow. The mean annual temperature is relatively mild $\left(-25.7^{\circ} \mathrm{C}\right)$. In winter, a mean temperature of $-30.1^{\circ} \mathrm{C}$ was measured, while the summer displayed a mean temperature of $-17.2^{\circ} \mathrm{C}$. Positive temperatures were never measured.

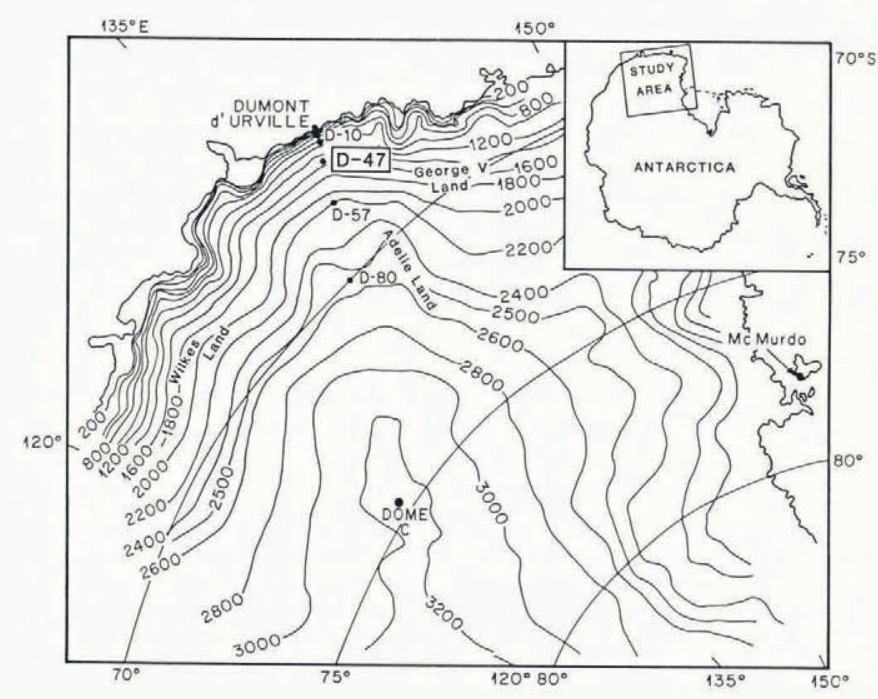

Fig. 1. Area map of Terre Adélie, Antarctica.

The mean annual wind speed at D-47 is high $\left(12.8 \mathrm{~m} \mathrm{~s}^{-1}\right)$. The maximum is observed in winter $\left(13.5 \mathrm{~m} \mathrm{~s}^{-1}\right.$, seasonal mean), while the minimum occurs in summer $\left(11.3 \mathrm{~m} \mathrm{~s}^{-1}\right)$. The directional constancy, which is defined as the ratio of the mean wind vector to the scalar average wind speed, has a very large mean annual value of 0.94 . It means that winds that do not come from a south-easterly direction blowing down the slope are rare occurrences. Winds have two effects on the albedo of snow: 
(1) Drifting and blowing snow is a very frequent occurrence. New snow is normally redistributed within hours. The mechanical action of the blowing snow destroys its crystalline structure and changes the albedo. Mean diameter of the crystals was measured at between 100 and $300 \mu \mathrm{m}$.

(2) The strong and persistent winds form sastrugi (snow dunes), which form and disappear again. Most of Terre Adelie is covered with them (Fig. 2), and they are usually directed along the line of the resultant wind vector. Since sastrugi are not randomly directed, they also have an effect on the albedo.

The following instrumentation was used:

PD-4 Davos pyranometer for short-wave incoming and reflected radiation.

Eppley Star pyranometer for short-wave incoming radiaion.

PD-1 Davos pyranometer as a portable instrument to measure albedo over different surfaces.

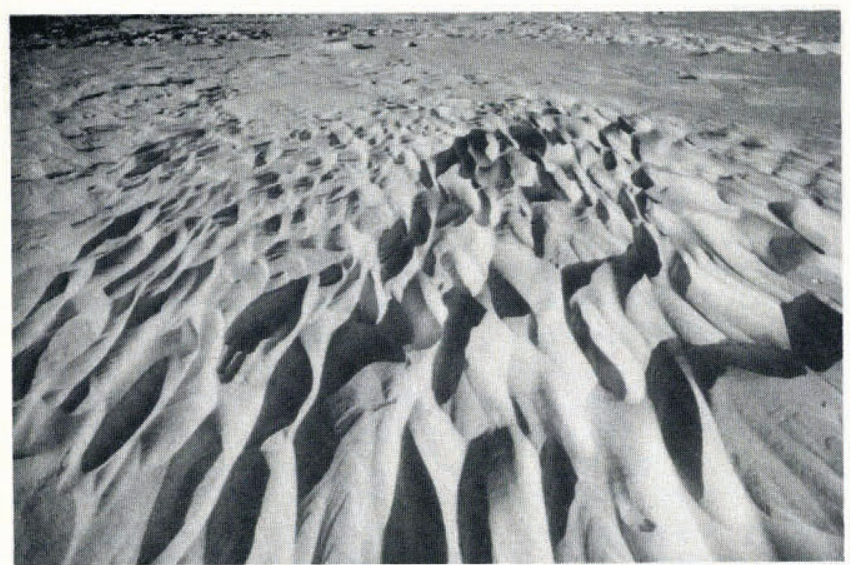

Fig. 2. A sastrugi field as observed at D-47, Terre Adélie, Antarctica. Sastrugi height: $20-30 \mathrm{~cm}$, in extreme cases: $1 \mathrm{~m}$

The instruments measure the whole visible and nearinfra-red spectrum. The glass domes (WG7 and 295) of the instruments have a wavelength range from 281 to $2800 \mathrm{~nm}$. As a calibration instrument, a Linke-Feussner actinometer (No. 700 207), which had been compared to the United States Standards in Boulder, Colorado, was used. All data, with the exception of the Linke-Feussner actinometer, were recorded on a Campbell CR 7 data logger. Measurements were taken every $10 \mathrm{~s}$. These data were averaged over $10 \mathrm{~min}$ intervals and recorded electronically as well as printed out in real time to yield immediate data control. The measurements were taken in November and December 1985. Calibration was carried out at the beginning and end of the observational period. Complete data sets are available for $33 \mathrm{~d}$. Of this period, $15 \mathrm{~d}$ were clear, $13 \mathrm{~d}$ were partly cloudy, and $5 \mathrm{~d}$ had overcast conditions.

\section{ALBEDO AND SOLAR ELEVATION}

Typical values of the albedo of the snow were about $80 \%$. These high values might be explained by the fact that our measuring site was situated above the dry-snow line (Benson, 1962), hence melting never occurred, nor was water ever present in the snow. When melting of snow does occur, values substantially lower are normally found (Dirmhirn and Trojer, 1955; Kelley, 1973; Wendler and Weller, 1974).

In Figure 3, the albedo is plotted for a totally cloudless day against the solar elevation. The area over which these measurements were made was flat. It can be seen that, for solar elevations above $12^{\circ}$, there is only a

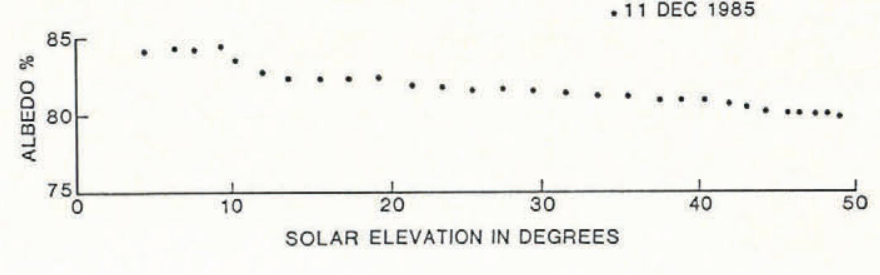

Fig. 3. Albedo of snow as a function of solar elevation for a totally clear day of summer 1985-86, Terre Adélie. Antarctica.

slight dependency of the albedo on the position of the Sun The observed change in reflectivity between $12^{\circ}$ and $49^{\circ}$ solar elevation is about $2.5 \%$. However, reflectivity increased further for very low Sun angles. For these data, the energy received decreases, hence the relative error increases Furthermore, most pyranometers have a cosine effect, which might become substantial for solar elevations of less than $5^{\circ}$. Hence, that part of the figure should not be given the same importance as the rest.

The results of these observations of variations in albedo are similar to other studies, for example, Ambach (1963) in Greenland, and Wendler and Streten (1969) in south-eastern Alaska. No dependency of albedo on solar elevation could be established for cloudy days.

\section{ALBEDO AND CLOUDINESS}

As long as no new snowfall occurs, the albedo is fairly constant for reasonably high solar elevations. However, large variations were observed when cloudiness appeared, which could not be explained by changes in snow conditions.

When clouds are present, the radiation received at the surface is diffuse, while under a clear sky about $85 \%$ of the incoming radiation is directed. As the diffuse and direct radiation have a somewhat different spectrum (Coulson, 1975), and the reflectivity of the snow is wave-dependent (Dirmhirn and Eaton, 1974), variations in the albedo are to be expected. More recently, Warren (1982) summarized the state of knowledge, and detailed work has been carried out by Carroll and Fitch (1981), Grenfell and others (1981), and Grenfell and Perovich (1984). Grenfell and others (1981) gave spectral albedos between 380 and $2500 \mathrm{~nm}$ for a snow cover in the Cascade Mountains, Grenfell and Perovich (1984) for partly snow-covered sea ice, and Carroll and Fitch (1981) worked at the South Pole. They showed clearly that the reflectivity of the snow in the short-wave (visible) part of the solar spectrum is very high $(>90 \%)$, while reflectivity in the near-infra-red region is substantially lower (about 20\% mean value for 1500-2500 nm). Warren and Wiscombe (1980) carried out theoretical calculations of the spectral albedo which are in good agreement with the measurements of the above-mentioned authors. As the energy of the solar spectrum in these larger wavelengths is low, a combined albedo of $83 \%$ for clean Antarctic snow is reasonable. Clouds also absorb more in the near-infra-red than the visible; a decrease of the infra-red component relative to the visible part of the irradiance with increasing cloud cover was determined by Grenfell and Perovich (1984). ? ; is further magnified if multiple reflection between ghly reflective surfaces occurs (Wendler and others, 1y81), and can result in a substantial increase in the albedo. Grenfell and Perovich (1984) found values up to $15 \%$ for Barrow, Alaska - similar to values presented here.

In Figure 4 the albedo of the snow surface is given for different types of cloud. For each case, six measurements are given, each consisting of the mean of 60 individual measurements. In general, it can be seen that the thicker the cloud, the higher the albedo. While clear-sky conditions yield albedo values of around $82 \%$, this value increased to $83.5 \%$ for cirro-stratus clouds, to $86.5 \%$ for alto-stratus clouds, and to even higher values for stratus cloud cover. The figure also shows that the scatter in the data points is more pronounced for cloudy conditions than for clear sky. This is understandable, as even the same kind 


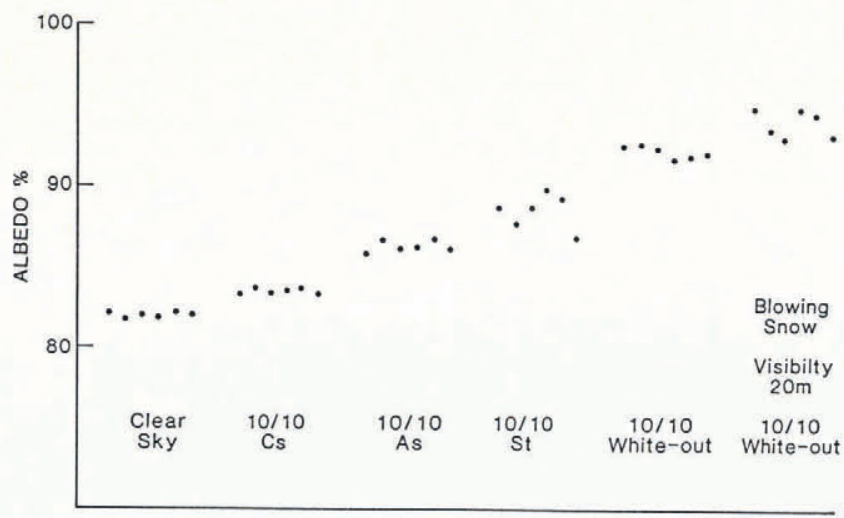

Fig. 4. Albedo of snow as a function of cloud type at D-47, Terre Adelie, Antarctica.

of clouds will have different thicknesses and hence different influences on multiple reflection and the solar spectrum. For white-out conditions, values of the albedo of up to $95 \%$ were observed.

\section{SNOW TYPE AND ALBEDO}

Different types of snow have different reflectivities. We were able to identify three distinct types, namely:

(a) Fresh snow.

(b) Redistributed but loose snow.

(c) Redistributed compacted snow.

In Table I, the albedos for the three types and smooth and uneven surfaces are given. Ten measurements were carried out for each type. All measurements were made around solar noon and under clear-sky conditions to minimize other effects on the albedo such as solar height and cloudiness.

TABLE I. TYPICAL VALUES OF ALBEDO FOR DIFFERENT SNOW TYPES. EACH SERIES CONSISTS OF TEN MEASUREMENTS; THE STANDARD DEVIATION IS ALSO GIVEN

Soft smooth level snow

Soft uneven snow (no shadows)

New fresh snow

Hard smooth level snow

Hard uneven snow (some shadows)

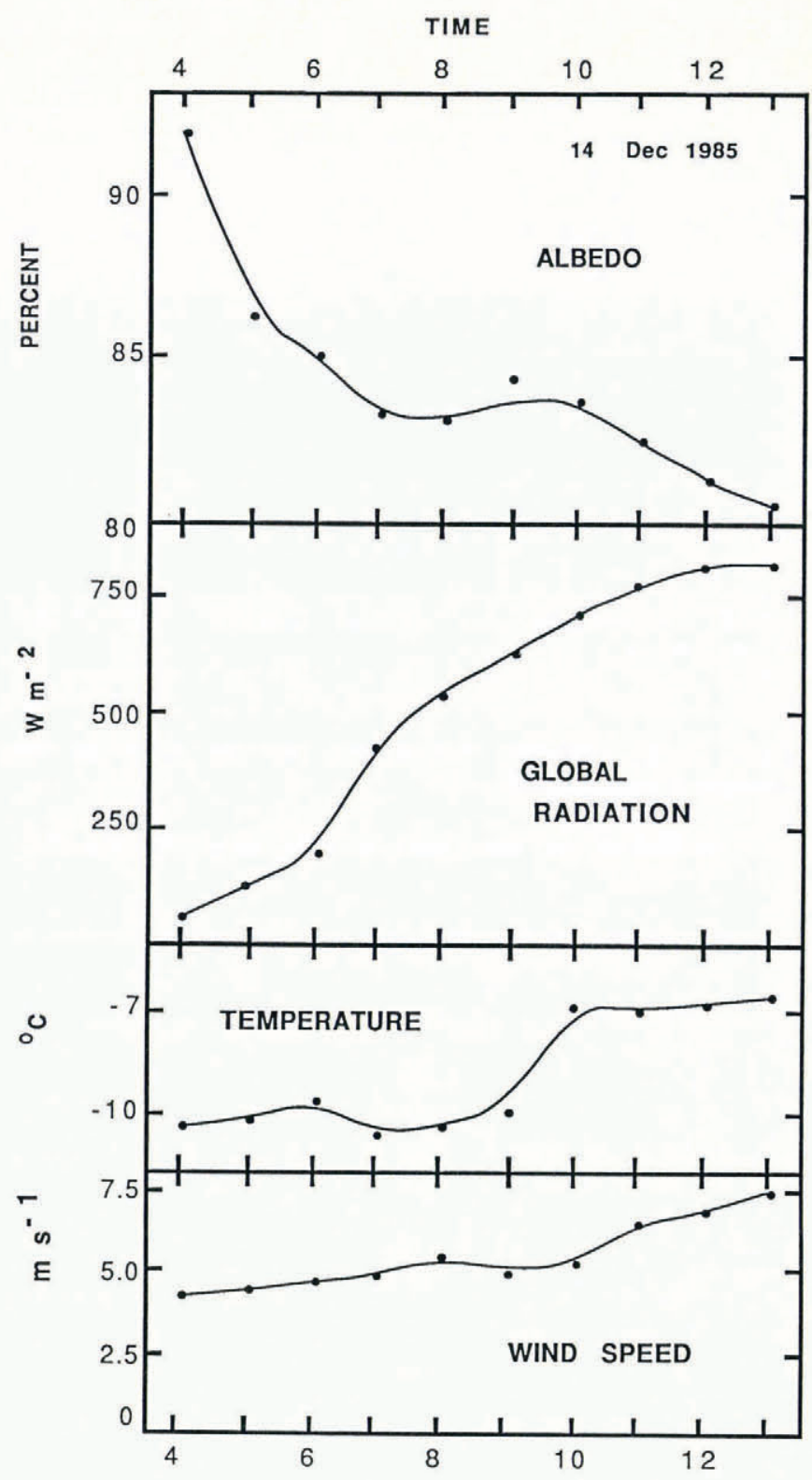

Fig. 5. The decrease of albedo after a new snowfall in the summer of 1985-86, Terre Adélie, Antarctica.
The fallen snow crystals are intact for freshly deposited snow, while for redistributed snow they are destroyed. Compressed snow has a substantial surface hardness. Frequently, no imprint of footsteps could be seen when walking over the surface. It can be seen from the table that the albedo of soft redistributed snow and compressed snow is similar. It is well known that new snow, however, displays a higher albedo (Hoinkes, 1960). In our case, new snow was associated with albedo values about $10 \%$ above those of the other snow types. The exact value of the freshly fallen snow will vary with the crystal form and its density.

During the night of 13-14 December 1985, it snowed at our measuring site. The early morning was totally cloudfree and an $8 \mathrm{~cm}$ layer of new snow covered the surface. Our measurements of the surface albedo in the very early morning $(04.00 \mathrm{~h})$ showed values above $90 \%$ (Fig. 5). However, by $13.00 \mathrm{~h}$ on the same day, the albedo was back to normal, with a value of just over $80 \%$. The figure also gives supporting meteorological parameters. It can be seen that the global radiation is strong which, together with the relatively mild temperatures, will cause recrystallization. The small crystals, of which the original snowflakes consist, will be destroyed, and larger but still small crystals are formed. We did not make measurements during the early morning but a photo-electric snow-blowing device (Wendler, in press) gave mean values of $150 \mu \mathrm{m}$ later in the day, after the wind speed had increased. Such a drop in albedo with increased grain-size has been reported previously, and occurs at all wavelengths (Warren, 1982). An increase in grain-size increases the path length that must be travelled between scattering opportunities, and with it the chance of the photon being absorbed.

\section{SASTRUGI AND ALBEDO}

Sastrugi can have a substantial influence on the albedo of snow, as they may cast a shadow. The size of the shadow will depend on the form and direction of the sastrugi, and the solar position, height, and azimuth. We carried out measurements of both incoming and reflected radiation over a flat surface with the PD-4 Davos. Furthermore, hand-held measurements at many places and fixed measurements for a few days at a time at one place were made over a sastrugi field with the PD-1 Davos. The interpretation of these data is complicated but can be clarified by modelling their effect on the albedo. As model 

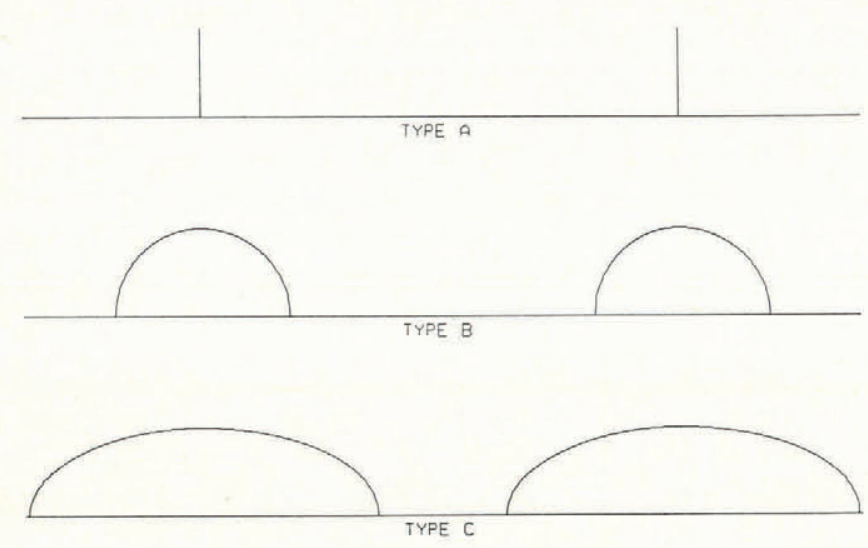

Fig. 6. Assumptions of sastrugi geometry for model calculations.

input, three different assumptions for the form of the sastrugi were made (Fig. 6):

(a) Sastrugi are considered as walls perturbing the snow surface.

(b) Sastrugi are considered as semi-circles perturbing the snow surface.

(c) Sastrugi are considered as ellipses perturbing the snow surface.

Cases (a) and (b) can be regarded as special situations of case (c). Referring to Figure 8, case (a) is the situation in which $a=0$, and in case (b) $a=b$. The azimuth $(A Z)$ and elevation $(E L)$ of the Sun were calculated for the time of the day and day of the year, using the method of Walraven (1978). The angle $(\varepsilon)$ at which the Sun's rays strike the horizontal surface is calculated from azimuth, elevation, and sastrugi direction $(D)$ using the equation:

$$
\varepsilon=\arctan \left[\frac{\tan (E L)}{\cos (A Z \times \mathrm{D}+\pi)}\right] .
$$

A coordinate system is then introduced with its origin at the center of the ellipse, and axes along the axes of the ellipse. The $(x, y)$ coordinate of the point at which the Sun's rays are tangential to the elliptical sastrugi is then calculated using the following series of equations.

$$
\begin{gathered}
c=\left(a^{2}-b^{2}\right)^{\frac{1}{2}}, \\
\alpha=\frac{\pi}{2}-\varepsilon, \\
\beta=\arcsin \left(\frac{c}{a} \sin \alpha\right), \\
r_{1}=2 c\left(\frac{\sin (\alpha-\beta)}{\sin (2 \beta)}\right), \\
r_{2}=2 a-r_{1}, \\
x=\frac{r_{2}^{2}-r_{1}^{2}}{4 c}, \\
y=\left\{r_{2}^{2}-(x+c)^{2}\right\}^{\frac{1}{2}}
\end{gathered}
$$

where $(-c, 0)$ and $(c, 0)$ are the foci of the ellipse, and $\alpha, \beta$, $r_{1}, r_{2}, x$, and $y$ are as in Figure 7 .

There are two possibilities for the percentage of the surface in shadow. In the first case (Fig. 8a), the shadow
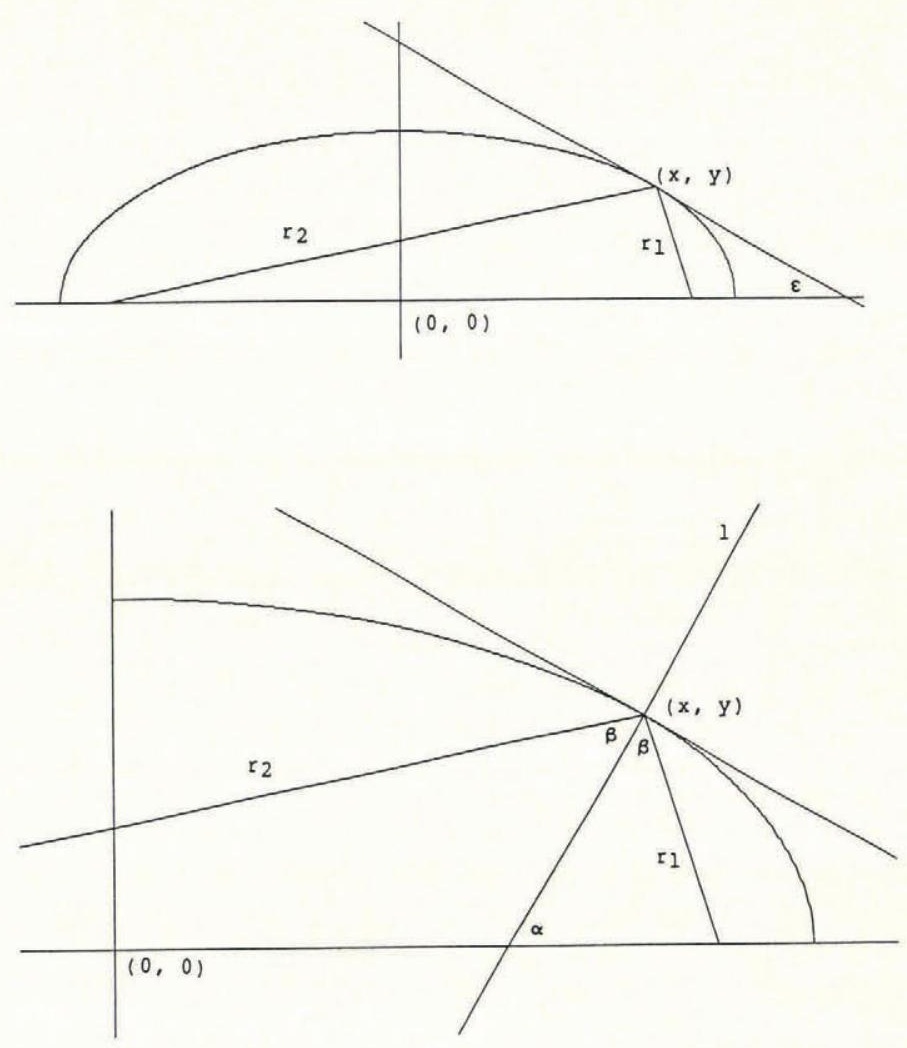

Fig. 7. Sastrugi model with features labelled.

$\varepsilon=$ angle at which the Sun's rays strike sastrugi.

$(x, y)=$ point at which the Sun's rays are tangential to sastrugi.

$r_{1}, r_{2}=$ radii of ellipse at $(x, y)$.

$l=$ perpendicular to the Sun's rays at the point $(x, y)$. Since the sastrugi are modelled as ellipses, this line bisects the angle between $r_{1}$ and $r_{2}$.

$\beta=$ angle between $l$ and radii.

$\alpha=$ angle formed by $l$ and the $x$-axis.
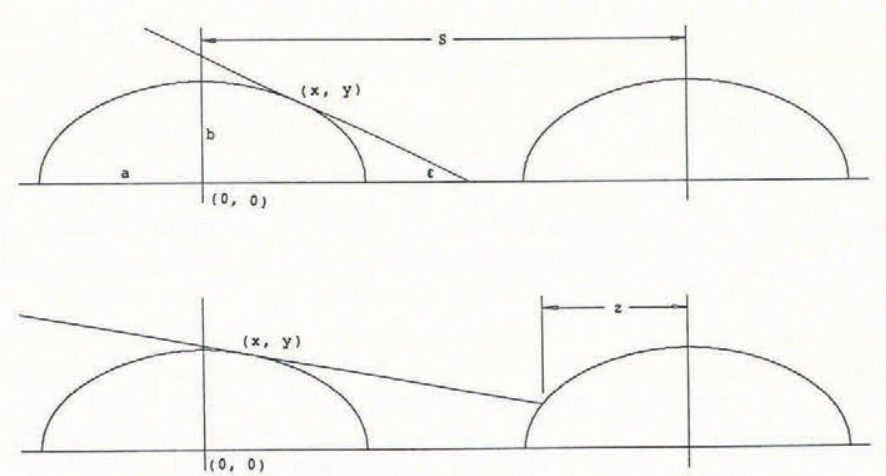

Fig. 8. Sastrugi model with features labelled.

$a=$ one-half the width of the sastrugi.

$b=$ height of sastrugi.

$S=$ distance between sastrugi.

$z=$ distance between the point at which the Sun's rays hit the adjacent sastrugi and the major axis of that sastruga.

does not reach the adjacent sastrugi. The percentage of surface in shadow is then given by the formula:

$$
100 y / S \tan (\varepsilon)
$$

where $S$ is the distance between the sastrugi, and $\varepsilon$ and $y$ are as above.

In the second case, at relatively low solar angles, the adjacent sastrugi interfere with the shadow (Fig. 8b). The percentage is given by: 


$$
100(S-x-z) / S
$$

where

$$
z=\frac{a\left[m t a+b\left(a^{2} m^{2}-t^{2}+b^{2}\right]^{\frac{1}{2}}\right.}{a^{2} m^{2}+b^{2}}
$$

and

$$
\begin{gathered}
m=\tan (-\varepsilon), \\
t=y m(x+S),
\end{gathered}
$$

$S, x, y, a, b$, and $\varepsilon$ are as above, and $z$ is as shown in Figure $8 \mathrm{~b}$.

For our model of the mean albedo we made two assumptions:

(1) The reflectivity of snow for a horizontal surface exposed to the Sun is $80 \%$ of the global radiation.

(2) The reflectivity of shaded snow, independent of its exposure, is $15 \%$ of the global radiaion.

Actually, the amount of sky radiation on the global radiation is somewhat smaller; however, multiple reflection between slopes of different exposure raises the radiation received on shaded surfaces.

Furthermore, for our calculations, a solar ephemeris of $20^{\circ}$ was assumed, which was about the value observed at the time we made our measurements.

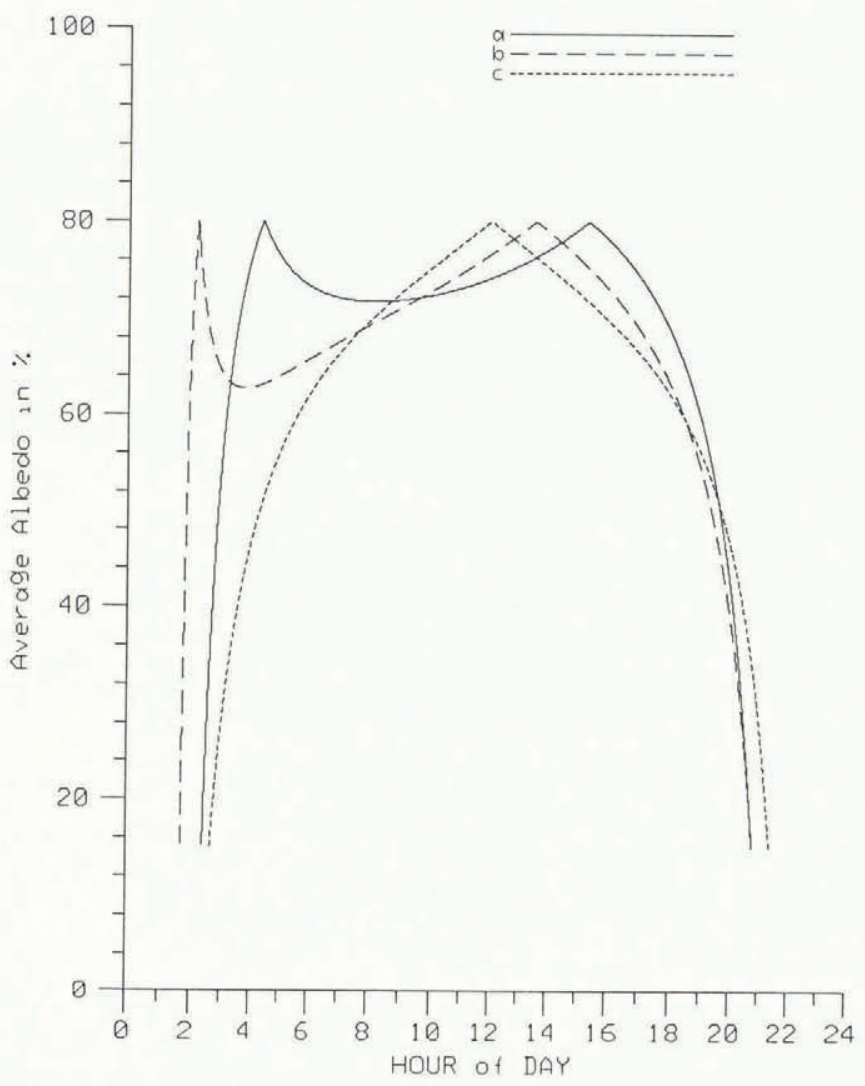

Fig. 9. The diurnal course of the albedo modelled for the following conditions: (1) Vertical walls, $a=0$. (2) Ratio of spacing $b: S=1: 10$. (3) Summer conditions (solar ephemeris $20^{\circ}$ ). (4) Sastrugi directions (a) $120^{\circ}$; (b) $150^{\circ}$; and (c) $180^{\circ}$.

In Figure 9, the calculations were carried out for case (a). A ratio of height to horizontal spacing is assumed to be 1:10. Three directions of the sastrugi are assumed: (a) North-south $\left(0-180^{\circ}\right)$;

(b) $150-330^{\circ}$;

(c) $120-300^{\circ}$.

Values between the latter two are normally found at the observational site, as the wind blows from south-easterly directions most frequently. Sometimes more than one sastrugi direction is observed, as can be seen from an aerial photograph which was taken over Terre Adélie during the observational period (Fig. 10). Figure 9 shows a diurnal variation of albedo which is symmetric about solar noon.

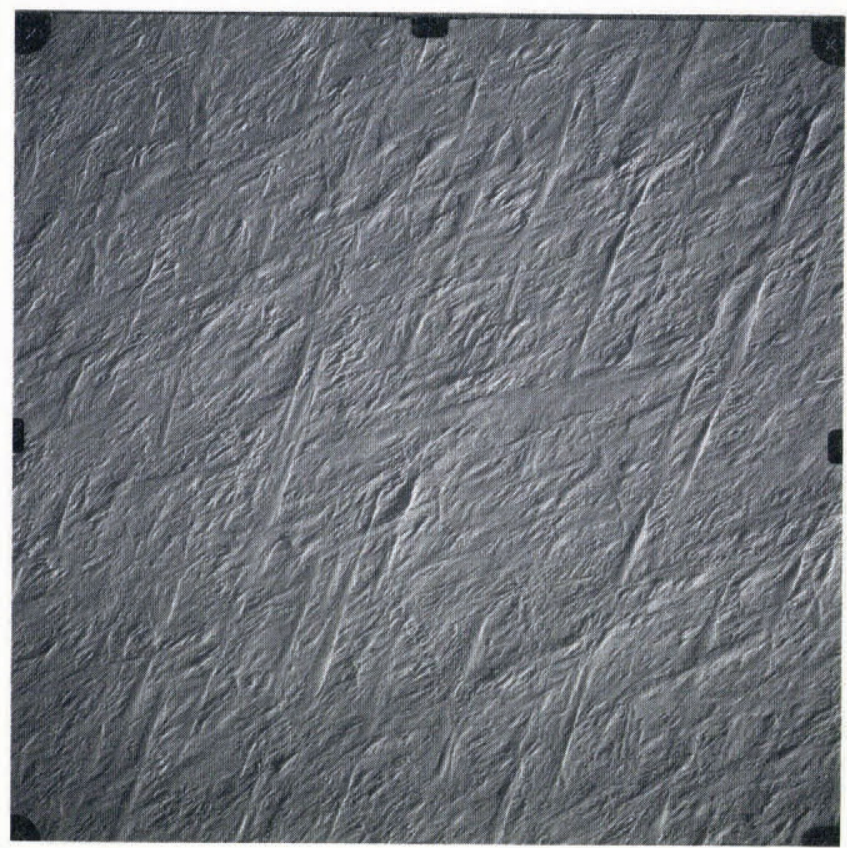

Fig. 10. Aerial photograph of a sastrugi field taken during the observational period. Note the two directions of the sastrugi.

The shadows become longer with decreasing solar height, and hence the effect on the albedo becomes more pronounced. For sastrugi directions of $150^{\circ}$ and $120^{\circ}$, no effect on the walls is observed around 14.00 and $16.00 \mathrm{~h}$ solar time, respectively, as the walls are parallel to the Sun's rays at these times. Otherwise, an asymmetric diurnal course of the albedo is observed. If the ratio of height to distance is lowered, the diurnal variation of the albedo becomes more pronounced as the shadowed areas become larger. In Figure 11, examples are given for $b: S$ ratios of $1: 10$ (as in Fig. 9), $1: 5$, and $1: 2$. Furthermore, 120-300 direction of the sastrugi and summer conditions were assumed. Due to space limitations, only a few examples can be shown; however, the model allows the variation to be calculated for any desired conditions.

If we go to type $C$ sastrugi, sastrugi direction was assumed to be $120^{\circ}$, the height to distance ratio $1: 10$, and summer conditions were assumed (solar ephemeris $20^{\circ}$ ); Figure 12 shows the results of the model. It can be seen that as the ratio $a: b$ gets smaller, the diurnal variation becomes more pronounced. The curve is nearly flat for $a: b=5: 1$. In Figure 13 the actual measured albedo over a sastrugi field is compared to a modelled one for three different sastrugi types. The detector integrates over several sastrugi. Measurements from 06.00 to $18.00 \mathrm{~h}$ are used. During these hours, the energy levels are high enough to obtain meaningful results. It can be seen that good agreement can be reached by manipulating the variables $a, b$, and $S$. The mean difference in the reflectivity is always less than $2 \%$ between modelled and measured data, and the modelled diurnal variation closely follows the actual measurements. $120-300^{\circ}$ was assumed as the sastrugi direction.

The asymmetric diurnal course of the albedo which was measured could be satisfactorily explained by the model. Furthermore, for other times of the year with lower solar 


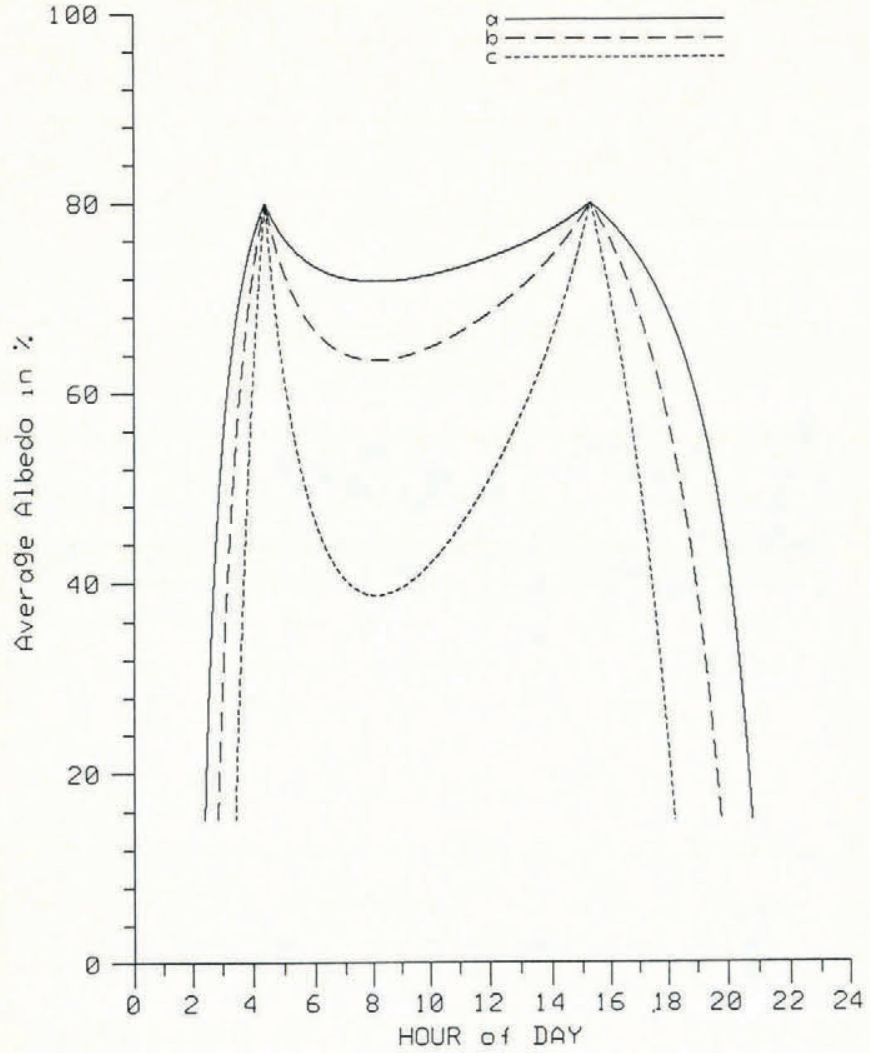

Fig. 11. The diurnal course of the albedo modelled for the following conditions: (1) Vertical walls, $a=0$. (2) Sastrugi direction $120-300^{\circ}$. (3) Summer conditions (solar ephemeris $20^{\circ}$ ). (4) Ratio of spacing $b: S=(a)$ $1: 10 ;(b) 1: 5$; and (c) $1: 2$.

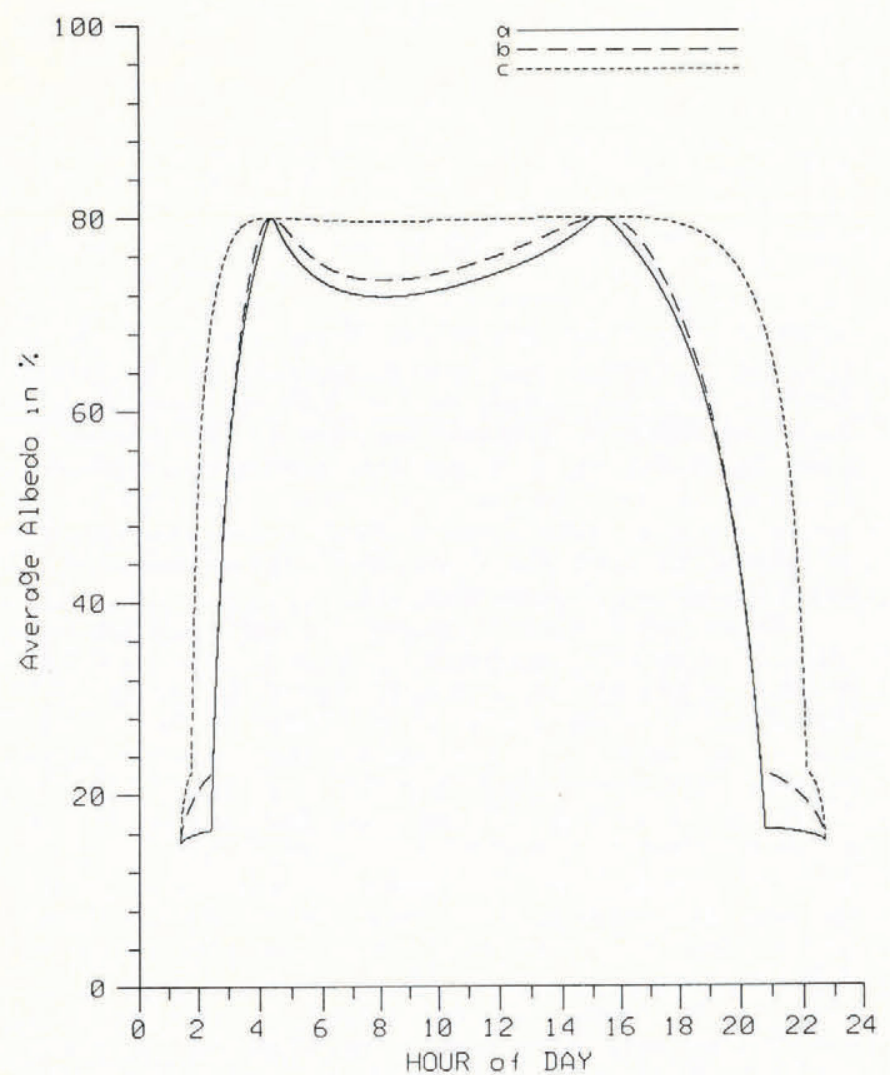

Fig. 12. The diurnal course of the albedo modelled for the following conditions: (1) Ratio of spacing $b: S=1: 10$. (2) Sastrugi direction 120-300 . (3) Summer conditions (solar ephemeris 20\%). (4) C-type sastrugi assumed (a) $a: b=1: 5 ;$ (b) $a: b=1: 1$ (type B); and (c) $a: b=5: 1$.

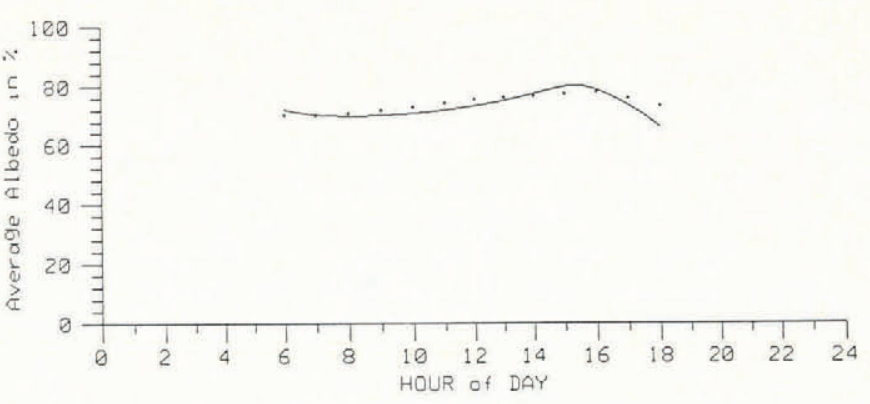

Fig. 13. Comparison of the actual measurements of the albedo at D-47 with modelled values. $a: b=9: 4$; $b: S=2: 35$. (1) Ratio of spacing $b: S=2: 35$. (2) Sastrugi direction 120-300 . (3) Summer conditions (solar ephemeris $20^{\circ}$ ). (4) C-type sastrugi assumed, $a: b=9: 4$.

elevations, this diurnal course could be modelled, which we did for solar ephemeris of $+10^{\circ}$ (about 20 October or 23 February) and $+5^{\circ}$ (about 7 October or 8 March). It can be seen from Figure 14 that, with decreasing solar heights, the diurnal variations of the albedo become more pronounced.

An improvement could be made in the model by varying the sastrugi direction through some distribution of possible values rather than assuming that all the sastrugi are straight and parallel. The assumption of parallel sastrugi puts the entire surface into the sunlight when the solar azimuth is the same as the sastrugi direction, even if the solar elevation is low. This causes the modelled albedo to be slightly higher than the observed albedo at these times of day, as can be seen around 06.00 and $16.00 \mathrm{~h}$ in Figure 13.

In order to alleviate this problem, the albedo was modelled using a normal distribution of sastrugi directions.

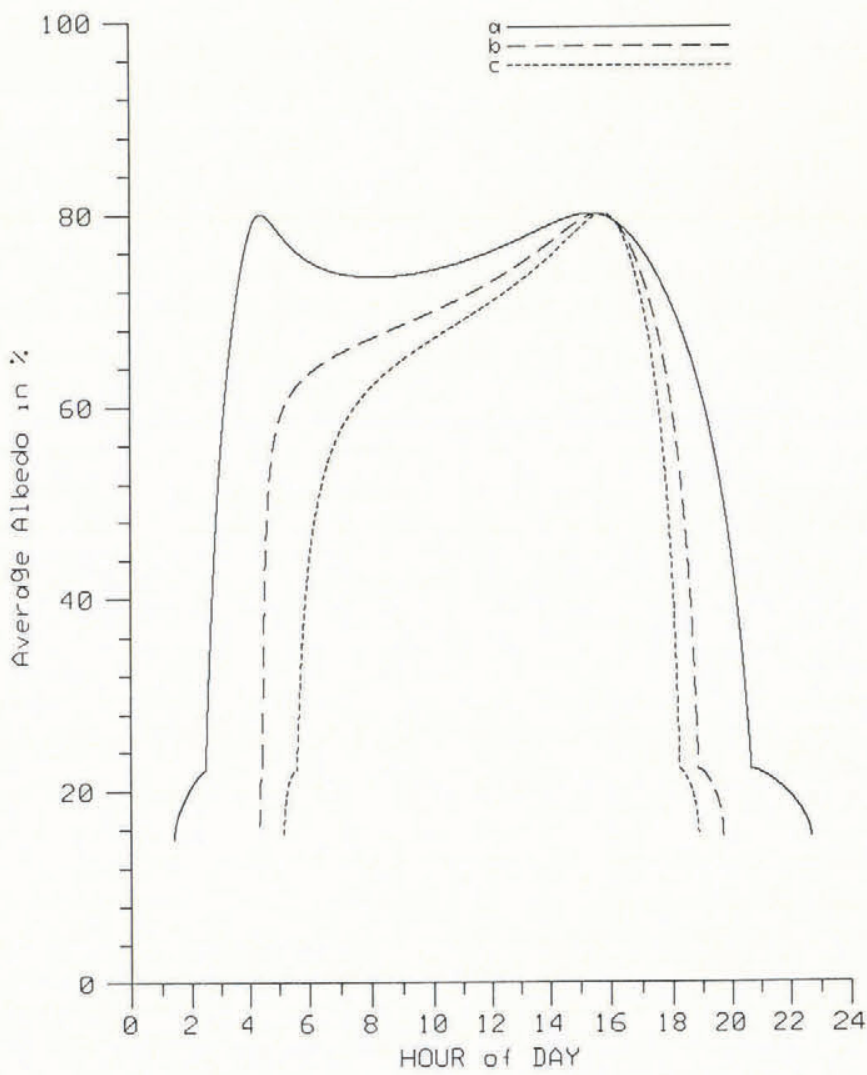

Fig. 14. Modelled diurnal course of the albedo for B-type $(a=b)$ sastrugi, and $a$ solar ephemeris of: $(a)+20^{\circ}$, (b) $+10^{\circ}$, and $(c)+5^{\circ}$ at $D-47$, Terre Adélie. 
The mean of this distribution was taken to be $120^{\circ}$, the same direction as was used in Figure 13. A numerical integration was performed over the range of the distribution to determine a new average modelled albedo. This method does not take into account the complex interference patterns of the several sastrugi directions; however, it is adequate for our purpose.

Some improvement was found in the average per cent difference between real and modelled values using this method. The minimum per cent difference of $1.42 \%$ was found when the standard deviation of the sastrugi direction was taken to be $25^{\circ}$. This compared with $2.03 \%$ average difference for the model with only one sastrugi direction.

\section{CONCLUSION}

Albedo was measured at an undisturbed site in Terre Adelie. The known dependency of reflectivity on snow type, solar elevation, and amount and type of cloudiness could be demonstrated. Warren (1982), in his review article, discussed and explained these phenomena. With the exception of new snowfalls, the dependence on snow type was not very pronounced, probably due to the fact that the crystal size did not vary substantially from one type to another. A blowing-snow device, which measured the mean size photoelectrically, normally gave values between 100 and $200 \mu \mathrm{m}$.

The effect of solar elevation is not very large for heights above $10^{\circ}$, and our instrumentation did not allow accurate measurements below this value. Cloudiness can have a substantial effect on the albedo, as the high-reflecting short-wave part of the solar spectrum is enhanced by multiple reflection between clouds and snow cover. Our values are in agreement with those found by Grenfell and Perovich (1984) north of Barrow.

However, the asymmetric variation of the albedo we measured could not be explained in this way. We developed a model, taking the form and direction of the sastrugi into account. Good agreement between model and field measurements was obtained. Furthermore, the albedo could be calculated for other times of the year, and it can be stated generally that the effect of the sastrugi on the albedo becomes more pronounced with decreasing solar elevations. It is believed that this last point of the paper is the most important finding.

\section{ACKNOWLEDGEMENTS}

This work was funded by U.S. National Science Foundation grant 810016. Furthermore, our thanks go to the United States Antarctic Research Program and Expéditions Polaires Françaises. Also, we thank our team members, R. Flint, Professor N. Ishikawa, Dr Y. Kodama, G. Mimken, P. Thiebaud, and J. Widget. Mr F. Brill carried out the computer work, for which we are grateful. Fruitful discussions with G. Mimken, while walking over the sastrugi fields, are gratefully acknowledged.

\section{REFERENCES}

Ambach, W. 1963. Untersuchungen zum Energieumsatz in der Ablationzone des grönländischen Inlandeises. Expédition Glaciologique Internationale au Groenland, E.G.I.G. 1957-1960, 4(4).

Benson, C.S. 1962. Stratigraphic studies in the snow and firn of the Greenland ice sheet. U.S. Army Snow, Ice and Permafrost Research Establishment. Research Report 70.

Carroll, J.J., and Fitch, B.W. 1981. Effects of solar elevation and cloudiness on snow albedo at the South Pole. Journal of Geophysical Research, 86(C6), 5271-76.

Coulson, K.L. 1975. Solar and terrestrial radiation; methods and measurements. New York, Academic Press.

Dimhirn, I., and Eaton, F. 1974. Some characteristics of the albedo of snow. Journal of Applied Meteorology, 14(3), 375-79.
Dimhirn, I., and Trojer, E. 1955. Albedountersuchungen auf dem Hintereisferner. Archiv für Meteorologie, Geophysik und Bioklimatologie, 6, 400.

Grenfell, T.C., and Perovich, D.K. 1984. Spectral albedos of sea ice and incident solar irradiance in the southern Beaufort Sea. Journal of Geophysical Research, 89(C3), 3573-80.

Grenfell, T.C., Perovich, D.K., and Ogren, J.A. 1981. Spectral albedos of an alpine snowpack. Cold Regions Science and Technology, 4(2), 121-27.

Hoinkes, H. 1960. Studies of solar radiation and albedo in the Antarctic (Little America V and South Pole, 1957/58. Archiv für Meteorologie, Geophysik und Bioklimatologie, 10, 175.

Ishikawa, N., Kobayashi, S., Ohata, T., and Kawaguchi, S. 1982. Some radiation properties at Mizuho Station, East Antarctica in 1980. Memoirs of National Institute of Polar Research, Special Issue 24, 19-31.

Kelley, J.J. 1973. Microclimatological investigations near the Arctic tundra surface. Proceedings of the 25th Anniversary of Naval Arctic Research Laboratory Symposium, 1972, 109-26.

Kuhn, M., Kundla, L.S., and Stroschein, L.A. 1977. The radiation budget at Plateau Station, Antarctica, 1966-1967. In Businger, J.A., ed. Meteorological studies at Plateau Station, Antarctica. Washington, DC, American Geophysical Union, 41-73. (Antarctic Research Series, 25.)

Liljequist, G.H. 1956. Energy exchange of an Antarctic snow-field. Norwegian-British-Swedish Antarctic Expedition, 1949-52. Scientific Results, 2(1A).

Mawson, D., Sir. 1915. The home of the blizzard; being the story of the Antarctic Australasian Expedition, 1911-1914. London, Heinemann.

Poggi, A., and 6 others. 1982. Interaction atmosphèreglace-océan en Antarctique. Météorologie, 1982, 163-71.

Renard, R.J., and Salinas, M.G. 1977. The history, operation and performance of an experimental automatic weather station in Antarctica. Monterey, CA, Naval Postgraduate School. (NPS-63Rd7710.)

Stearns, C.R., and Savage M.L. 1981. Automatic weather stations, 1980-1981. Antarctic Journal of the United States, 16(5), 190-92.

Walraven, R. 1978. Calculating the position of the Sun. Solar Energy, 20, 393-97.

Warren, S.G., 1982. Optical properties of snow. Reviews of Geophysics and Space Physics, 20(1), 67-89.

Warren, S.G., and Wiscombe, W.J. 1980. A model for the spectral albedo of snow. II. Snow containing atmospheric aerosols. Journal of the Atmospheric Sciences, 37(12), 2734-45.

Wendler, G. In press. On the blowing snow in Adélie Land, eastern Antarctica - a contribution to I.A.G.O. Proceedings of the Symposium on Glacier Fluctuations and Climatic Change, Amsterdam. June 1987.

Wendler, G., and Kodama, Y. 1985. Some results of climatic investigations of Adelie Land, eastern Antarctica. Zeitschrift für Gletscherkunde und Glazialgeologie, 21, 319-27.

Wendler, G., and Poggi, A. 1980. Measurements of the catabatic wind in Antarctica. Antarctic Journal of the United States, 15(5), 193-95.

Wendler, G., and Streten, N. 1969. Short term heat balance study on a Coast Range glacier. Pure and Applied Geophysics, 77, 68-77.

Wendler, G., and Weller, G. 1974. A heat balance study on McCall Glacier, Brooks Range, Alaska: a contribution to the International Hydrological Decade. Journal of Glaciology, 13(67), 13-26.

Wendler, G., Eaton, F.D., and Ohtake, T. 1981. Multiple reflection effects on irradiance in the presence of Arctic stratus clouds. Journal of Geophysical Research, 86(C3), 2049-57.

Yamanouchi, T. 1983. Variations of incident solar flux and snow albedo on the solar zenith angle and cloud cover at Mizuho Station, Antarctica. Journal of the Meteorological Society of Japan, 161(6), 879-92. 